Review Article

\title{
Successful Strategies to Engage Research Partners for Translating Evidence into Action in Community Health: A Critical Review
}

\author{
Jon Salsberg, ${ }^{1}$ David Parry, ${ }^{1}$ Pierre Pluye, ${ }^{2}$ Soultana Macridis, ${ }^{3}$ \\ Carol P. Herbert, ${ }^{4}$ and Ann C. Macaulay ${ }^{1}$ \\ ${ }^{1}$ Participatory Research at McGill, Department of Family Medicine, McGill University, 5858 Chemin de la Côte-des-Neiges, \\ Suite 300, Montreal, QC, Canada H3S 1Z1 \\ ${ }^{2}$ Department of Family Medicine, McGill University, 5858 Chemin de la Côte-des-Neiges, Suite 300, Montreal, QC, Canada H3S 1Z1 \\ ${ }^{3}$ Department of Kinesiology \& Physical Education, McGill University, 475 Pine Avenue West, Montreal, QC, Canada H2W $1 S 4$ \\ ${ }^{4}$ Department of Family Medicine, Schulich School of Medicine \& Dentistry, University of Western Ontario, \\ 1151 Richmond Street, London, ON, Canada N6A 3K6
}

Correspondence should be addressed to Jon Salsberg; jon.salsberg@mcgill.ca

Received 17 October 2014; Accepted 1 February 2015

Academic Editor: Habibul Ahsan

Copyright (C) 2015 Jon Salsberg et al. This is an open access article distributed under the Creative Commons Attribution License, which permits unrestricted use, distribution, and reproduction in any medium, provided the original work is properly cited.

\begin{abstract}
Objectives. To undertake a critical review describing key strategies supporting development of participatory research (PR) teams to engage partners for creation and translation of action-oriented knowledge. Methods. Sources are four leading PR practitioners identified via bibliometric analysis. Authors' publications were identified in January 1995-October 2009 in PubMed, Embase, ISI Web of Science and CAB databases, and books. Works were limited to those with a process description describing a research project and practitioners were first, second, third, or last author. Results. Adapting and applying the "Reliability Tested Guidelines for Assessing Participatory Research Projects" to retained records identified five key strategies: developing advisory committees of researchers and intended research users; developing research agreements; using formal and informal group facilitation techniques; hiring co-researchers/partners from community; and ensuring frequent communication. Other less frequently mentioned strategies were also identified. Conclusion. This review is the first time these guidelines were used to identify key strategies supporting PR projects. They proved effective at identifying and evaluating engagement strategies as reported by completed research projects. Adapting these guidelines identified gaps where the tool was unable to assess fundamental PR elements of power dynamics, equity of resources, and member turnover. Our resulting template serves as a new tool to measure partnerships.
\end{abstract}

\section{Introduction}

The creation and timely translation of action-oriented knowledge can rest on meaningful engagement with end-users, even before the research begins $[1,2]$. Participatory research (PR) (following Cargo and Mercer [3] and Green et al [4] and we use PR as an umbrella term to include all partnered research, including community-based participatory research (CBPR), action research, participatory action research, participatory evaluation, community engagement and patient engagement), and community engagement continue to attract increased attention as an approach to research, requiring formation of teams of researchers in partnerships with those affected by the issue under study in the community [3-5] and those who will utilize the results to effect change $[6,7]$. Overall, the literature suggests that the PR partnership approach increases the relevance of research questions [3, $5,8]$, with the potential for effective knowledge translation $[9,10]$, leading to faster uptake of evidence into practice [11]. For these reasons research granting agencies, including the National Institutes of Health (NIH), the Patient Centered Outcomes Research Institute (PCORI), and the Canadian Institutes of Health Research (CIHR), are increasingly requiring that researchers partner with community members, 


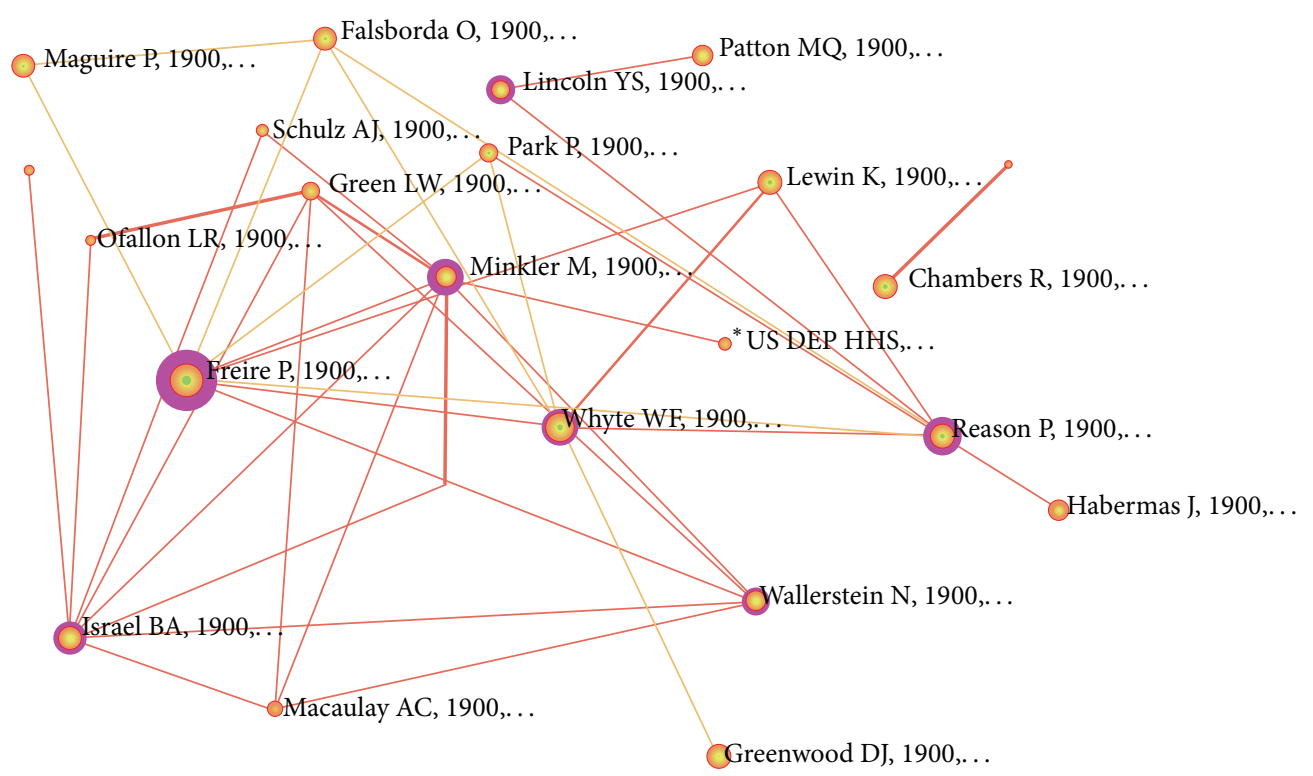

Figure 1

patients, health professionals, health organisations, and policy makers, resulting in many more researchers adopting a participatory approach.

In 1995, Green and colleagues developed guidelines intended to allow reviewers of funding agencies to assess stakeholders' engagement in PR projects [4, 12]. In 2008, these guidelines were further refined and reliability was tested to develop the Reliability Tested Guidelines for Assessing Participatory Research Projects [13] as a tool to (i) help funding agencies and peer reviewers to assess the participatory nature of proposals submitted for funding as participatory research; (ii) aid evaluators in assessing the extent to which projects meet participatory research criteria; and (iii) assist researchers and intended users of the research (i.e., nonacademic partners) in strengthening the participatory nature of their project proposals and applications for funding $[12,13]$. In 2009 van Olphen et al. [14] applied these guidelines for the first time, to a single project to assess to what extent their research was participatory as perceived by community, advocacy, and scientific partners. The authors concluded that this had been a very useful undertaking and that "further research should focus on the adaptation of PR principles to assist in evaluating the process and outcomes of PR [14]."

As the principles of the PR approach are used in a wide variety of research and contexts, there is a need to explore the following questions: What are the key processes of PR and what are the practical ways to achieve equitable partnerships? What processes support the constant negotiation between all team members for research goals and objectives, partner roles and responsibilities, and decision-making procedures, together with balancing knowledge generation with the need for action? Therefore, the purpose of this study is to build on recommendations [14] and use the 2008 Reliability Tested Guidelines to undertake a critical literature review of PR projects to synthesize key practical strategies that foster a successful PR process, resulting in continuous discussions between partners that will in turn facilitate knowledge translation activities throughout the research [15].

\section{Materials and Methods}

2.1. Data Sources. A critical review goes beyond the description of primary studies and includes an empirical analysis for exploring new ideas [16]. While critical reviews are criticized for their nonsystematic approach, "the 'critical' component of this type of review is key to its value" [16].

To begin, a multidisciplinary bibliographic database (ISI Web of Science) was searched using the phrase "participatory research" for all articles from 1995 (when the initial PR guidelines were published) until October 2009 (which was the year after the Reliability Tested Guidelines were published). Results of this search yielded 1866 publications. These were then imported into CiteSpace-a bibliometric network analysis tool (http://cluster.cis.drexel.edu/ cchen/citespace/)which generated a map of author-citation frequency. Results contained foundational PR scholars such as Paulo Freire and theoreticians including Peter Reason as well as those with practical PR experience. Our selection tool eliminated theoretical/foundational authors and retained only authors that have conducted practical PR studies. For this review we needed to limit the size of the study and chose to retain only the top four leading PR practitioners using their CiteSpace centrality scores: Barbara A. Israel, Meredith Minkler, Nina Wallerstein, and Ann C. Macaulay (Figure 1).

Next, a librarian-mediated search was conducted for all published materials by these four authors in PubMed, Embase, ISI Web of Science, PsychInfo, and CAB (Ovid database) for abstracts between January 1995 and October 2009. In addition we also reviewed chapters from books edited by these authors [17-19]. Duplicates were removed, for a total of 151 records (title, authors, source, and abstract). 


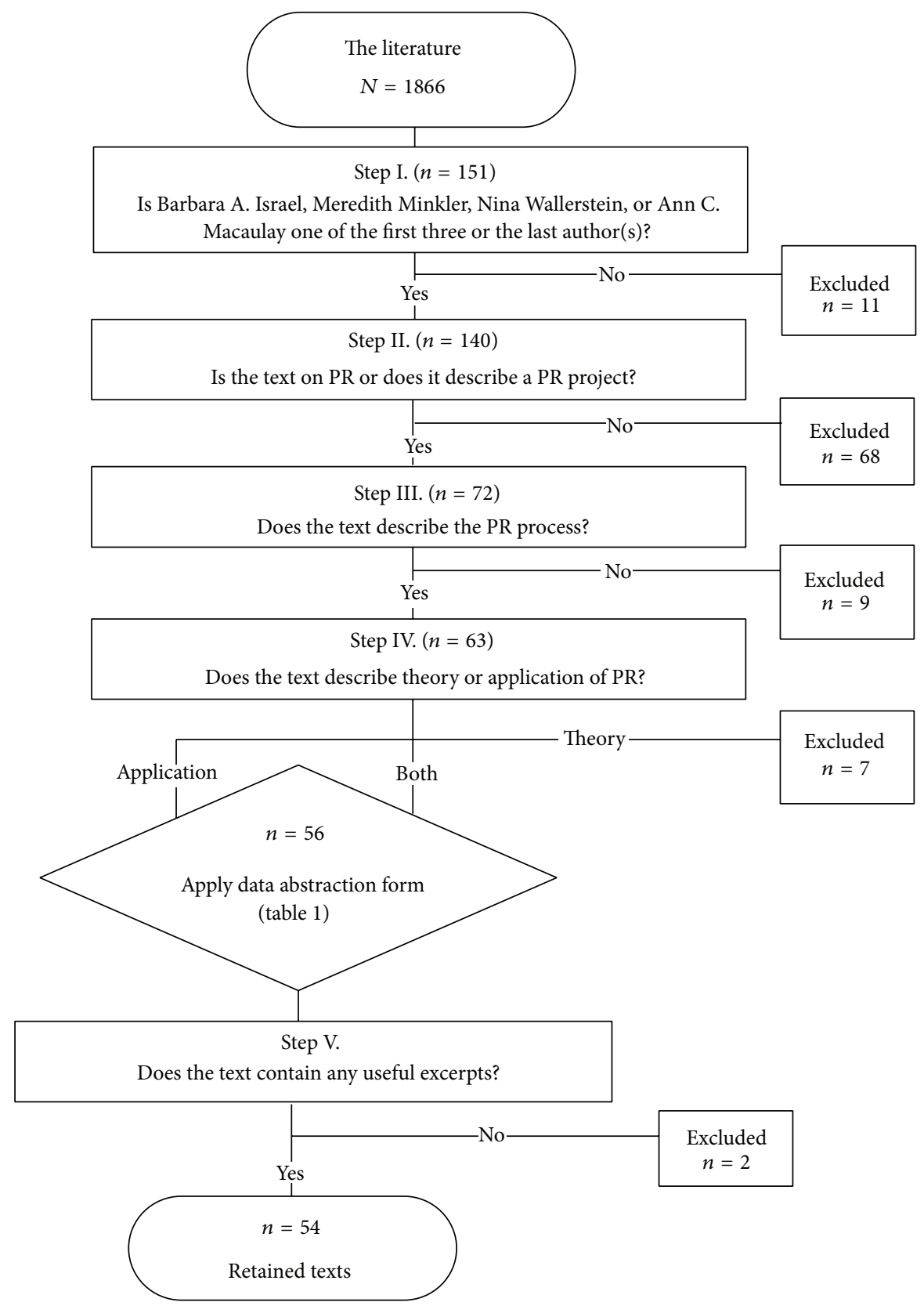

Figure 2

2.2. Study Selection. A staged selection process was then completed to limit the sample using eligibility criteria. First, records were excluded when one of the abovementioned PR leaders was neither one of the first three authors nor the last author $(n=11)$ to ensure that the leader had substantive input into the work. The second step excluded records that were not PR related $(n=68)$. The third step excluded records that did not contain any description of the PR process $(n=9)$ or records that contained only the theory of PR $(n=7)$. In the final step, records were excluded when they did not contain useful excerpts $(n=2)$, leaving 54 retained records (Figure 2).
2.3. Data Extraction. We conducted a deductive qualitative thematic analysis to extract useful data from our sample of documents [20]. For each of the 54 retained documents, relevant excerpts were selected and compiled in a Word document and organized by theme. These themes were derived from the partnership-related dimensions of the Reliability Tested Guidelines for Assessing Participatory Research Projects [13]. These guidelines contain 25 questions, 21 of which target the PR partnership process, making them very suitable to serve as themes for data extraction and analysis. These questions informed our coding scheme to identify PR 
process strategies. Using a coding grid based upon these questions (Table 1), partnership process-specific excerpts from the retained documents were extracted for analysis. Each retained document was reviewed in its entirety, and all excerpts in those documents that directly answered one of the questions were extracted and compiled in a matrix of "data by theme" for further analysis. Data coding was nonexclusive, and each excerpt could be coded to one or more questions on the coding grid.

2.4. Data Analysis. Data abstraction and coding were undertaken by one author (David Parry) using nonspecialized software (MS Word), which is appropriate for a deductive qualitative data analysis using a limited number of themes (codes). Each excerpt extracted from the retained documents was assigned to one or more themes, which was verified by a second author (Pierre Pluye or Jon Salsberg). Disagreements were discussed for possible resolution, and any that could not be resolved were adjudicated by a third party (Jon Salsberg for Pierre Pluye and vice versa). Using a constant comparative technique, themes were collapsed into overarching categories. These categories were generated through initial and focused coding techniques by comparing and contrasting text segments and sorting codes into conceptually meaningful units [21]. For example, subthemes such as "advisory committee," "steering committee," and "planning committee" were all grouped under the main theme "committee."

\section{Results}

Table 2 presents the references of the 54 documents that were retained for analysis and are organized by the four main authors. From these documents, 186 excerpts were assigned or coded to one or more than one theme. Of those, there was agreement between the reviewers for 180 (97\%) of excerpts. For the six remaining excerpts where there was disagreement, consensus was reached on five, and final judgment was sought from a third author (Jon Salsberg) for one excerpt.

The five most frequently mentioned strategies for fostering a researcher-community partnership are listed (unranked) and described in Table 3. These are forming an advisory board, developing a research agreement, using group facilitation techniques, hiring from the community, and having frequent meetings.

The remaining less frequently mentioned strategies are summarized in Table 4, which we felt could not be collapsed into categories without losing individual substance. However we consider these examples as also being extremely important for researchers to put into practice, including the need for researchers to make active efforts to reach out and learn about their partners and their communities; facilitating engagement by being flexible and working around schedules of the partners; understanding community priorities and culture; establishing clear lines of communication; speaking frankly and agreeing to disagree; building community capacity; supporting partners interpretation of data; publishing results in community; including nonacademic partners as copresenters and coauthors; working with community partners to build resources based on results; using the results to influence policy; and regular evaluation of the partnerships.

\section{Discussion}

This is a first step in a larger research agenda to identify variation in PR practices across contexts and partnership stages that could in the future be drawn on to answer the question of efficacy of $\mathrm{PR}$ practices. As this review was exploratory and not systematic, we decided to include a purposeful sample of included studies. CiteSpace helped us to elicit a criterion for a purposeful sampling. The rationale was that most cited papers for our review played a role similar to "key informants" in primary research. Given that this study had limited resources, we focused on the top four authors (most popular "key information resources").

From the four authors identified, committees such as steering committees and advisory committees are the most frequently mentioned strategy as a way to engage key stakeholders around the table from the beginning-including patients, practitioners, service managers, communities and the public, and policy makers. The second most frequently mentioned strategy is drafting research agreements, which some recommend should be done early in the partnership in order to avoid misunderstandings and because the process of developing written agreements or partnership principles is in itself a partnership building process $[72,74]$. However, the authors of this paper are also aware of teams who have not wanted a written agreement, either for cultural reasons where a verbal agreement is deemed very final, or due to the fact that it could be construed to imply lack of trust between the researchers and the partners. Our review results show that group facilitation is often suggested as a way to offer equal opportunity for partners to participate in discussions and to afford more reserved partners the chance to voice their opinion. Facilitation includes informal group discussions and formal techniques with many techniques borrowed from management. Hiring staff from the community increases credibility of the research, adds cultural relevance, builds capacity, promotes empowerment, provides work, brings in finances, and integrates knowledge translation throughout the process. Finally, frequent meetings are essential to maintain open communication as research evolves and to manage different expectations.

Table 4 shows many other additional practical strategies and supports the importance of meeting the needs of various partnerships in a wide range of contexts. It also emphasises the need for researchers to learn more about community issues and fully engage community members throughout the research process including interpretation of data and dissemination of results both internally within the community where the research was undertaken and externally.

To our knowledge, this is the first time the Reliability Tested Guidelines have been used to undertake a critical literature review to document PR partnership processes. The strengths of this review include (i) using a bibliometric methodology to identify leading PR practitioners, (ii) a comprehensive identification of PR studies conducted by these 


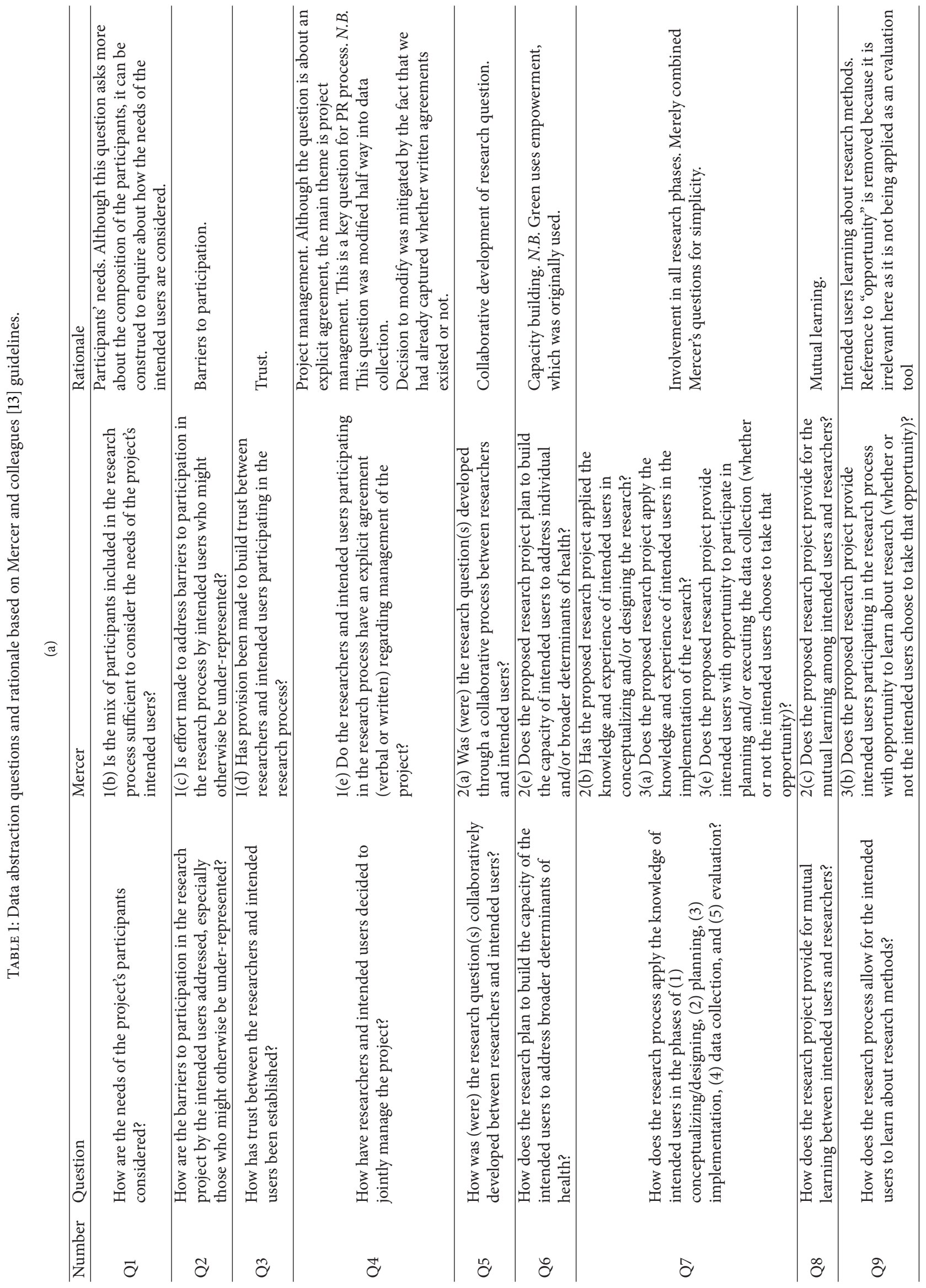




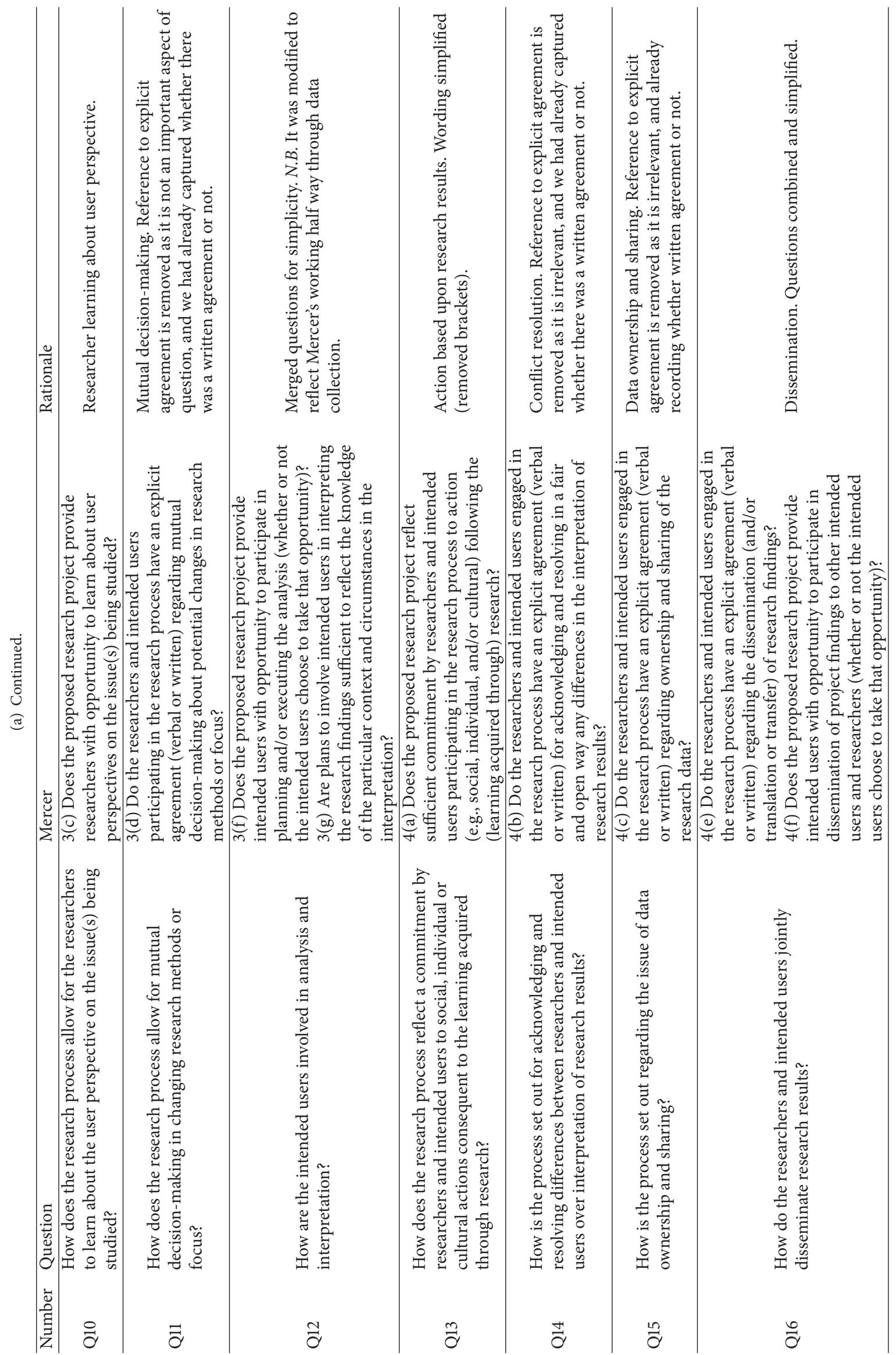




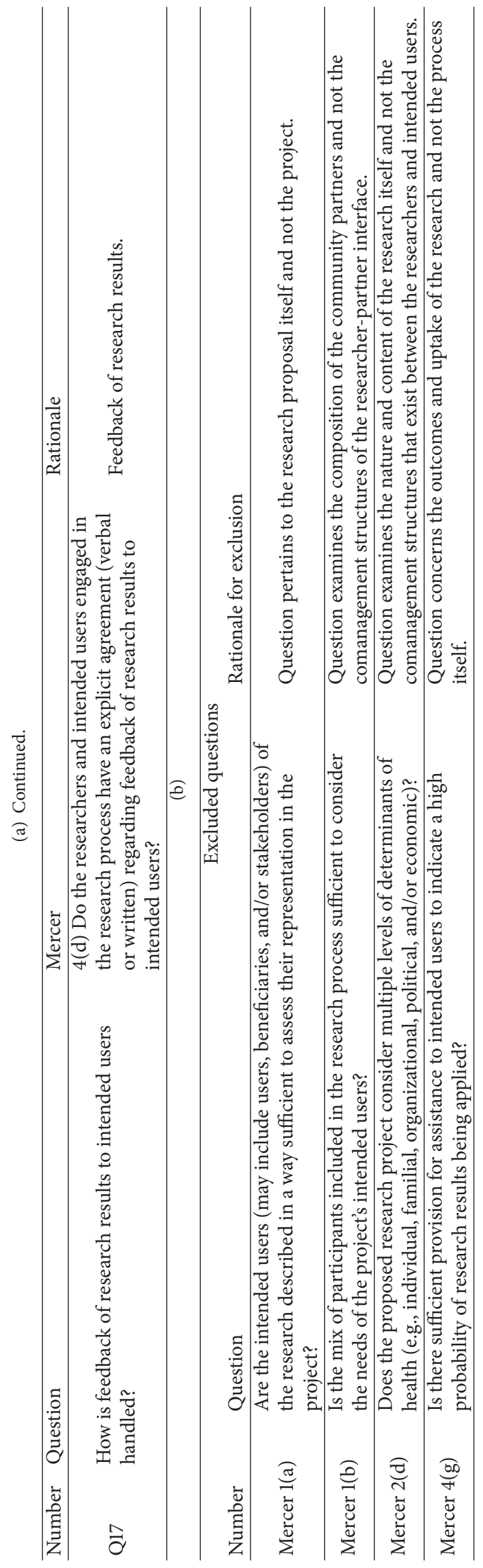




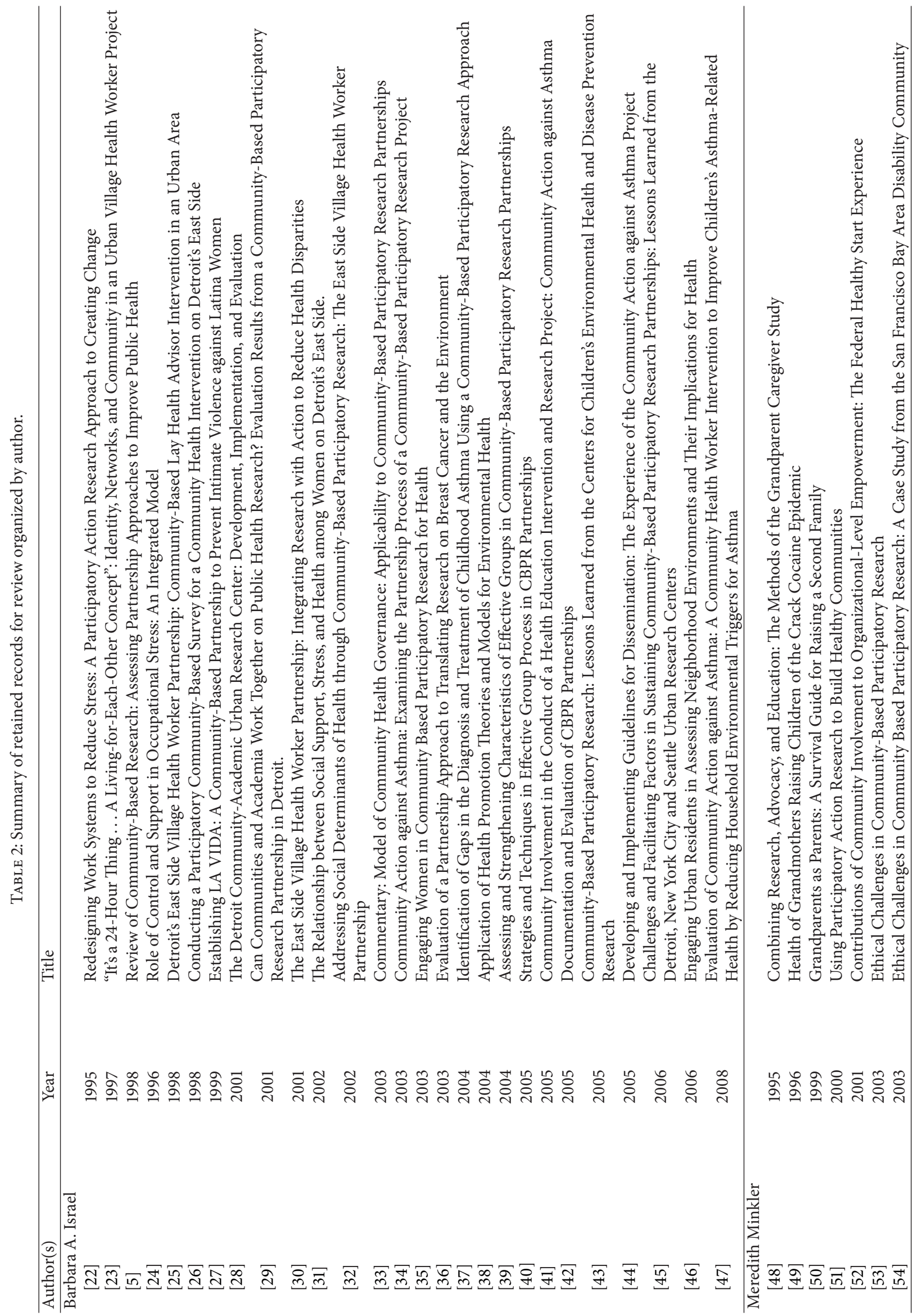




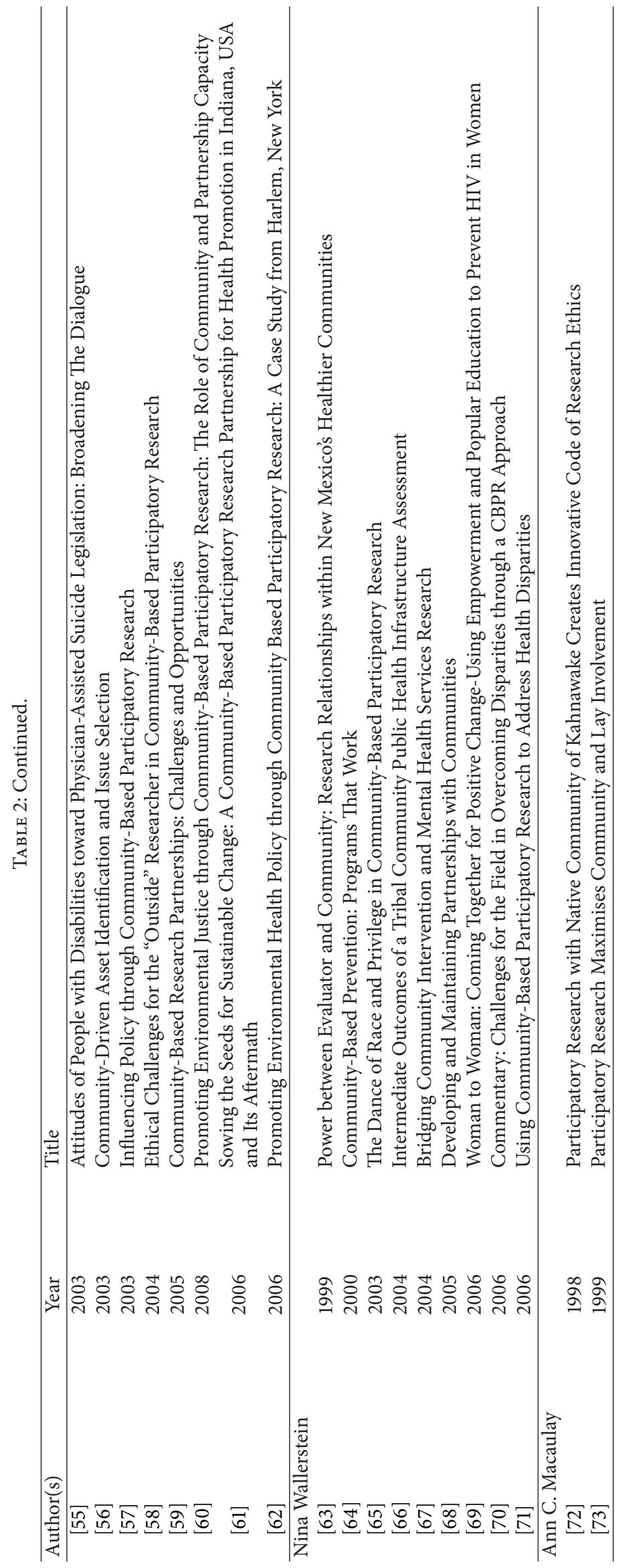


TABLE 3: Summary and description of the most frequently mentioned strategies for developing a research-community partnership.

\begin{tabular}{|c|c|}
\hline Strategy & Description \\
\hline $\begin{array}{l}\text { (1) Development of an } \\
\text { advisory committee }\end{array}$ & $\begin{array}{l}\text { (i) Acomposition of researchers, the intended users of the research, and/or representatives of community } \\
\text { organizations } \\
\text { (ii) Advisory committees allow for inclusion of all viewpoints throughout the research process and joint } \\
\text { development of dissemination strategies and action plans } \\
\text { (iii) Subcommittees are often used to divide up tasks (e.g., reviewing new proposed research topics, } \\
\text { articles for publication, partnership evaluation) }\end{array}$ \\
\hline $\begin{array}{l}\text { (2) Development of } \\
\text { research agreements }\end{array}$ & $\begin{array}{l}\text { (i) Before the research begins, clearly spell out researchers and partner roles and responsibilities, outline } \\
\text { how decisions will be made (e.g., by consensus or by voting), and set out what to do if conflict arises } \\
\text { (ii) Research agreements may also include plans for data ownership and control, interpretation of data, } \\
\text { and procedures for resolving disagreement over research results } \\
\text { (iii) Developing agreements is seen as a trust-building exercise }\end{array}$ \\
\hline $\begin{array}{l}\text { (3) Use of group } \\
\text { facilitation techniques }\end{array}$ & $\begin{array}{l}\text { (i) Can be both a formal and an informal process to ensure meaningful involvement and participation of } \\
\text { partners } \\
\text { (ii) Formal facilitation includes focus groups, workshops, and nominal group techniques } \\
\text { (iii) Informal techniques include circulating agendas ahead of time, small group work, and one-on-one } \\
\text { informal discussions }\end{array}$ \\
\hline $\begin{array}{l}\text { (4) Hiring staff from the } \\
\text { community of study }\end{array}$ & $\begin{array}{l}\text { (i) Hiring local persons as project staff recognizes community members' abilities to establish good } \\
\text { relationships with individual participants for recruitment and ongoing data collection } \\
\text { (ii) Projects hire well-respected community members as a "community champions," field coordinators, } \\
\text { intervention staff, interviewers, and group cofacilitators, for data collection and analysis. }\end{array}$ \\
\hline $\begin{array}{l}\text { (5) Frequent } \\
\text { communication }\end{array}$ & $\begin{array}{l}\text { (i) Communication between partners through regular group meetings to keep all partners updated on } \\
\text { progress and changes in procedures and as a way of discussing concerns and challenges } \\
\text { (ii) Other methods include telephone calls to partners who missed meetings to bring them up-to-date and } \\
\text { prompt circulation of meeting minutes and newsletters }\end{array}$ \\
\hline
\end{tabular}

authors, (iii) a transparent selection of relevant documents describing PR partnership processes, and (iv) a reproducible deductive qualitative data thematic analysis using the Reliability Tested Guidelines as basis for a coding scheme to analyze relevant excerpts from retained documents. This critical review has also identified that the four authors reviewed utilise these processes and also reestablished the Reliability Tested Guidelines as reliable criteria by which to measure partnerships.

It is noteworthy that four or fewer excerpts were identified for the following Reliability Tested Guidelines dimensions: mutual learning (Q8), conflict resolution over interpretation of results (Q14), and data ownership and sharing (Q15). This is surprising considering that mutual learning is a fundamental PR principle and the latter two are key issues to be resolved for any PR project. More literature on these topics would be very useful; for example, Jagosh and colleagues found that successful conflict resolution led to further strengthening of the teams [75].

This review also highlights gaps that the Reliability Tested Guidelines do not address. These include (i) the issues of power dynamics and recommendations for ways of decentralizing power and decision-making either through subcommittees or through a high level of local control, (ii) ways to address issues of equity of resources, that is, equitable sharing of resources across community organizations and researchers, or providing grants or other funding to participating community-based organizations, and (iii) the common problem of adding or replacing new members throughout the project-which causes shifting group dynamics. We also recognize that more other human aspects of partnerships have not been addressed, including the time needed to consolidate partnerships, issues of power differences, personality clashes, and institutional cultures.

There is much diversity in the strategies discussed by the four PR leaders. This is particularly encouraging for three reasons. First, it suggests that $\mathrm{PR}$ is highly adaptable to many contexts and settings and the iterative nature of this research approach. As PR is rapidly expanding beyond its earlier application in health promotion with marginalized communities, this adaptability will become increasingly important for partnerships with new types of communities including communities of practice and organizations such as practice-based research networks [76] and also for partnering with patients and policy makers. Second, research teams can find many strategies in the results to draw upon when starting out. A given strategy does not always work for a given context and the whole team can discuss potential alternative strategies. Third, the diversity of results reinforces the notion that the PR process is an active, iterative endeavour, requiring energy and flexibility from all partners. The findings are supported by other authors including a critical review by Cargo and Mercer [3] and incorporated by Wallerstein and Duran [10] in a conceptual logic model of community-based participatory research. For those embarking on PR there are recommendations and training curricula from individual teams [76-78] and organisations [74, 79-81] on how to build $\mathrm{PR}$ teams and maintain equitable partnerships throughout the research process, including dissemination of the results. There are also an increasing number of publications on the 
TABLE 4: Summary and description of less frequently mentioned strategies for developing a research-community partnership.

Strategy $\quad$ Examples

(i) Attending community-organized educational sessions or going on a community tour

(i) Researchers need to make active efforts to learn about the participants and their context (ii) Arranging retreats with community members

(iii) Organizing structured workshops with community members, as well as having informal conversations with them

(iv) Conducting formal interviews with community organizations

(v) Actively involving intended users through hiring study staff from the community and utilizing a community organizer/champion

(vi) Forming advisory board for the project with representation from organizations implicated in the research

(i) Be flexible with partners' work schedules and negotiate with their employers for study-related tasks

(ii) Utilize community contacts for recruitment of marginal community members or make use of "snowball" referral

(ii) Facilitate intended user involvement

(iii) Reach out to places frequented by community members (e.g., schools)

(iv) Adopt group facilitation techniques

(v) Approach partners individually for input away from larger groups

(vi) Understand community priorities and culture

(vii) Speak frankly and agree to disagree

(viii) Include representation in the project from both those affected directly by the research and the community as a whole

(ix) Evaluate the partnership frequently to elicit partners' feelings

(i) Take time at the beginning to get to know one another and keep frequent contact with intended users

(ii) Spend time in the community (e.g., attend significant community events)

(iii) Establish lines of communication

(iii) Jointly develop a written research agreement clearly spelling out roles and responsibilities of all partners

(iv) Follow through on the agreement and any other promises

(v) Hire community members as project staff

(i) Include wide representation from key community organizations where implemented

(ii) Jointly develop operating norms including decision-making, conflict resolution, and meeting facilitation

(iii) Adopt consensus decision-making

(iv) Form a community-led board

(iv) Hold monthly meetings, rotate meeting locations if possible, and circulate draft agendas and meeting minutes

(v) Include intended users in the management structure by hiring a respected community leader for their project's primary leadership role to facilitate community connections, share perspectives, and provide project oversight

(v) Group

facilitation

techniques; an iterative process when deciding upon research goals and grounded research question(s)

(vi) Build community capacity

(i) Utilize and develop community resources and support networks when conducting research

(ii) Train community members as cofacilitators of research activities

(iii) Involve the community in needs assessment and planning processes

(i) The community can be involved in all phases of research

(ii) Ensure active involvement of community members in all study tasks (e.g., reviewing all study documents to

(vii) Outline community involvement in research agreements ensure they are in an understandable language)

(iii) Solicit suggestions from community partners through focus groups or meetings (e.g., on data collection approaches)

(iv) Hire and train lay community members or utilize an advisory board as field coordinators, interviewers, data collectors, intervention staff, and analysts (e.g., identification of variables, selection of measures, and questionnaire development)

(i) Provide training to community about health issues

(ii) Use training sessions to get community perspective on these issues

(iii) Have community members critique preexisting research instruments as a way of learning about developing

(viii) Community training in research questionnaires and for researchers to learn about the community's perspective

(iv) Teach community public health and research skills

(v) Conduct community workshops on research methods

(vi) Use focus groups to engage community members in discussions about research in their community 
TABLE 4: Continued.

\begin{tabular}{|c|c|}
\hline Strategy & Examples \\
\hline $\begin{array}{l}\text { (ix) Engage in early } \\
\text { community } \\
\text { interactions while } \\
\text { developing the } \\
\text { project }\end{array}$ & $\begin{array}{l}\text { (i) Conduct in-depth interviews with community members and other key informants } \\
\text { (ii) Go on "wind-shield" tours driving around the community } \\
\text { (iii) Involve community in developing context-specific models } \\
\text { (iv) Make use of qualitative data } \\
\text { (v) Use theoretical, convenience, and open sampling }\end{array}$ \\
\hline $\begin{array}{l}\text { (x) Advisory } \\
\text { committee }\end{array}$ & $\begin{array}{l}\text { (i) Set up a subcommittee of the advisory committee to review all partnership evaluation results and make } \\
\text { recommendations to the overall advisory committee } \\
\text { (ii) Advisory committee can facilitate data analysis and interpret results } \\
\text { (iii) Present and discuss results with community partners to facilitate interpretation } \\
\text { (iv) Researchers and community members can analyze data independently and present their interpretations } \\
\text { (v) Engage in open, interactive analysis with community partners } \\
\text { (vi) Adopt a research agreement at the beginning outlining community involvement in results interpretation }\end{array}$ \\
\hline (xi) Action $\mathrm{p}$ & $\begin{array}{l}\text { (i) Establish action groups of community partners to develop intervention strategies and plan policy initiatives } \\
\text { (ii) Work with community members in deciding upon policy initiatives and action plans } \\
\text { (iii) Instrumental use of research results to lobby government } \\
\text { (iv) Work with community partners to develop community resources based upon study results } \\
\text { (v) Hold meetings with community partners to discuss other nonstudy-related, important issues }\end{array}$ \\
\hline $\begin{array}{l}\text { (xii) Interpretation, } \\
\text { data ownership, and } \\
\text { dissemination }\end{array}$ & $\begin{array}{l}\text { (i) Community partners can communicate their own interpretation of study data along with researcher study } \\
\text { publications } \\
\text { (ii) Adopt a no veto rule, meaning that neither researchers nor community partners can block a publication } \\
\text { with results } \\
\text { (iii) Spell out this process in a written researcher agreement before it arises } \\
\text { (iv) Researchers can be guardians of the data during the project, but transfer data control to community after } \\
\text { the project ends } \\
\text { (v) Community obligation is to allow researchers the right to on-going data analysis } \\
\text { (vi) Develop dissemination strategy outlining community involvement } \\
\text { (vii) Include nonacademic partners as coauthors/copresenters on manuscripts/abstracts } \\
\text { (viii) Disseminate results through local organizations, newspapers, media, and community-based practitioners } \\
\text { (ix) Jointly publish a community newsletter with results included } \\
\text { (x) Make use of local cultural mechanisms, such as street theatre } \\
\text { (xi) Circulate a summary report to community members and/or have feedback/discussion sessions } \\
\text { (xii) Organize debriefing sessions with a luncheon or gala celebration } \\
\text { (xiii) Discuss publication drafts with the community before submission }\end{array}$ \\
\hline
\end{tabular}

experiences of both academic [82] and community [83, 84] team members from their participatory research experiences and documented common characteristics of successful community-institutional partnerships [85].

While this review provided an innovative synthesis of key PR strategies for researchers using a PR approach, a limitation is that it is based on only four authors' publications. Because the review included book chapters not limited to the word count restrictions of journal articles we may have captured more details than from journal articles alone. There are no standard recommendations for reporting on PR; from this review we recommend that journal editors require the key stages from the Reliability Tested Guidelines to be included, which would facilitate future synthesis. Our results consist of strategies that could be tested and explored in greater detail through a larger systematic literature review, which may include more detailed descriptions of applied strategies for planning and sustaining PR partnerships. Such a systematic review might be able to rank these strategies in terms of their effectiveness in different contexts, which would first require further basic research into the efficacy of particular participatory strategies and their effectiveness in generating and translating new knowledge into action. As
PR is becoming more accepted, this new evidence is slowly emerging within the fields of participatory research as well as in implementation and translational science.

\section{Conclusion}

This review is the first to adapt the Reliability Tested Guidelines for Assessing Participatory Research Projects to identify leading processes that support PR partnerships. Five key practical strategies to foster a successful PR process are identified that in turn integrate knowledge translation throughout the research process. Some of these results have already been incorporated into the Canadian Institutes for Health Research (CIHR) Guide to Researcher and KnowledgeUser Collaboration in Health Research [81]. One colleague remarked, "I will print these 5 strategies in big color letters and pin them in front of my desk. No one can remember 25 questions, while anybody can handle 5 ideas per day." The guidelines, originally intended to allow funders to assess partnership engagement in grant applications, proved effective at identifying and evaluating the same engagement strategies as reported by completed research projects. Adapting these guidelines for our use identified gaps where the tool was 
unable to assess the fundamental PR elements of power dynamics, equity of resources, and member turnover. Our resulting template serves as a new tool for research teams to apply to measure their own partnerships.

\section{Conflict of Interests}

The authors declare that there is no conflict of interests regarding the publication of this paper.

\section{Acknowledgments}

This work was partially supported through a grant from the Lawson Foundation, ON, Canada.

\section{References}

[1] S. Bowen and I. D. Graham, "Integrated Knowledge Translation," in Knowledge Translation in Healthcare: Moving from Evidence to Practice, E. Straus, J. Tetroe, and I. D. Graham, Eds., pp. 14-23, Wiley/BMJ Books, Oxford, UK, 2013.

[2] J. Salsberg, A. C. Macaulay, and D. Parry, "Guide to integrated knowledge translation research," in Turning Knowledge into Action: Practical Guidance on How to Do Integrated Knowledge Translation Research, I. D. Graham, J. Tetroe, and A. Pearson, Eds., pp. 178-182, Wolters Kluwer, Lippincott Williams \& Wilkins, JBI, Adelaide, Australia, 2014.

[3] M. Cargo and S. L. Mercer, "The value and challenges of participatory research: strengthening its practice," Annual Review of Public Health, vol. 29, pp. 325-350, 2008.

[4] L. W. Green, M. A. George, M. Daniel et al., Study of Participatory Research in Health Promotion, Royal Society of Canada, Ottawa, Canada, 1995.

[5] B. A. Israel, A. J. Schulz, E. A. Parker, and A. B. Becker, "Review of community-based research: assessing partnership approaches to improve public health," Annual Review of Public Health, vol. 19, pp. 173-202, 1998.

[6] I. D. Graham, J. Logan, M. B. Harrison et al., "Lost in knowledge translation: time for a map?" The Journal of Continuing Education in the Health Professions, vol. 26, no. 1, pp. 13-24, 2006.

[7] L. W. Green and S. L. Mercer, "Can public health researchers and agencies reconcile the push from funding bodies and the pull from communities?" The American Journal of Public Health, vol. 91, no. 12, pp. 1926-1929, 2001.

[8] M. W. Leung, I. H. Yen, and M. Minkler, "Community-based participatory research: a promising approach for increasing epidemiology's relevance in the 21st century," International Journal of Epidemiology, vol. 33, no. 3, pp. 499-506, 2004.

[9] E. J. Trickett, S. Beehler, C. Deutsch et al., "Advancing the science of community-level interventions," American Journal of Public Health, vol. 101, no. 8, pp. 1410-1419, 2011.

[10] N. Wallerstein and B. Duran, "Community-based participatory research contributions to intervention research: the intersection of science and practice to improve health equity," The American Journal of Public Health, vol. 100, supplement 1, pp. S40-S46, 2010.

[11] L. W. Green, "Making research relevant: if it is an evidencebased practice, where's the practice-based evidence?" Family Practice, vol. 25, no. 1, pp. i20-i24, 2009.
[12] L. W. Green, Guidelines and Categories for Classifying Participatory Research Projects in Health, lgreen.net, 2014, http:// lgreen.net/guidelines.html.

[13] S. L. Mercer, L. W. Green, M. Cargo et al., "Appendix C: reliability-tested guidelines for assessing participatory research projects," in Community-Based Participatory Research for Health: From Process to Outcomes, M. Minkler and N. Wallerstein, Eds., pp. 407-433, Jossey-Bass, San Francisco, Calif, USA, 2008.

[14] J. van Olphen, J. Ottoson, L. Green, J. Barlow, K. Koblick, and R. Hiatt, "Evaluation of a partnership approach to translating research on breast cancer and the environment," Progress in Community Health Partnerships: Research, Education, and Action, vol. 3, no. 3, pp. 213-226, 2009.

[15] A. Kitson, K. Powell, E. Hoon, J. Newbury, A. Wilson, and J. Beilby, "Knowledge translation within a population health study: how do you do it?” Implementation Science, vol. 8, no. 1, article 54, 2013.

[16] M. J. Grant and A. Booth, "A typology of reviews: an analysis of 14 review types and associated methodologies," Health Information and Libraries Journal, vol. 26, no. 2, pp. 91-108, 2009.

[17] B. A. Israel, E. Eng, A. J. Schulz, and E. A. Parker, Eds., Methods in Community-Based Participatory Research for Health, JosseyBass, San Francisco, Calif, USA, 2005.

[18] M. Minkler and N. Wallerstein, Eds., Community Based Participatory Research for Health, Jossey-Bass, San Francisco, Calif, USA, 2003.

[19] M. Minkler and N. Wallerstein, Eds., Community-Based Participatory Research for Health: From Process to Outcomes, JosseyBass, San Francisco, Calif, USA, 2nd edition, 2008.

[20] P. Paillé, "De l'analyse qualitative en général et de l'analyse thématique en particulier," Recherches Qualitatives, vol. 15, pp. 179-194, 1996.

[21] J. Lofland and L. H. Lofland, Analyzing Social Settings: A Guide to Qualitative Observation and Analysis, Wadsworth, Belmont, Calif, USA, 1995.

[22] "Redesigning work systems to reduce stress: a participatory action research approach to creating change," in Job Stress Interventions, S. J. Schurman and B. A. Israel, Eds., pp. 235-263, American Psychological Association, Washington, DC, USA, 1995.

[23] A. J. Schulz, B. A. Israel, A. B. Becker, and R. M. Hollis, "'It's a 24-hour thing ... a living-for-each-other concept': identity, networks, and community in an urban village health worker project," Health Education and Behavior, vol. 24, no. 4, pp. 465480, 1997.

[24] E. Baker, B. Israel, and S. Schurman, "Role of control and support in occupational stress: an integrated model," Social Science and Medicine, vol. 43, no. 7, pp. 1145-1159, 1996.

[25] E. A. Parker, A. J. Schulz, B. A. Israel, and R. Hollis, "Detroit's East Side Village Health Worker Partnership: communitybased lay health advisor intervention in an urban area," Health Education and Behavior, vol. 25, no. 1, pp. 24-45, 1998.

[26] A. J. Schulz, E. A. Parker, B. A. Israel, A. B. Becker, B. J. Maciak, and R. Hollis, "Conducting a participatory community-based survey for a community health intervention on Detroit's east side.," Journal of Public Health Management and Practice, vol. 4, no. 2, pp. 10-24, 1998.

[27] B. J. Maciak, R. Guzman, A. Santiago, G. Villalobos, and B. A. Israel, "Establishing LA VIDA: a community-based partnership 
to prevent intimate violence against Latina women," Health Education and Behavior, vol. 26, no. 6, pp. 821-840, 1999.

[28] B. A. Israel, R. Lichtenstein, P. Lantz et al., "The Detroit Community-Academic Urban Research Center: development, implementation, and evaluation," Journal of Public Health Management and Practice, vol. 7, no. 5, pp. 1-19, 2001.

[29] P. M. Lantz, E. Viruell-Fuentes, B. A. Israel, D. Softley, and R. Guzman, "Can communities and academia work together on public health research? Evaluation results from a communitybased participatory research partnership in Detroit," Journal of Urban Health, vol. 78, no. 3, pp. 495-507, 2001.

[30] A. J. Schulz, B. A. Israel, E. A. Parker, M. Lockett, Y. Hill, and R. Wills, "The East Side Village Health Worker Partnership: integrating research with action to reduce health disparities," Public Health Reports, vol. 116, no. 6, pp. 548-557, 2001.

[31] B. A. Israel, S. A. Farquhar, A. J. Schulz, S. A. James, and E. A. Parker, "The relationship between social support, stress, and health among women on Detroit's east side," Health Education and Behavior, vol. 29, no. 3, pp. 342-360, 2002.

[32] A. J. Schulz, E. A. Parker, B. A. Israel, A. Allen, M. Decarlo, and M. Lockett, "Addressing social determinants of health through community-based participatory research: the east side village health worker partnership," Health Education and Behavior, vol. 29, no. 3, pp. 326-341, 2002.

[33] B. A. Israel, "Commentary: model of community health governance: applicability to community-based participatory research partnerships," Journal of Urban Health-Bulletin of the New York Academy of Medicine, vol. 80, no. 1, pp. 50-53, 2003.

[34] E. A. Parker, B. A. Israel, M. Williams et al., "Community action against asthma: examining the partnership process of a community-based participatory research project," Journal of General Internal Medicine, vol. 18, no. 7, pp. 558-567, 2003.

[35] A. J. Schulz, B. A. Israel, E. A. Parker, M. Lockett, Y. R. Hill, and R. Wills, "Engaging women in community based participatory research for health," in Community Based Participatory Research for Health, M. Minkler and N. Wallerstein, Eds., pp. 293-315, Jossey-Bass, San Francisco, Calif, USA, 2003.

[36] J. van Olphen, A. Schulz, B. Israel et al., "Religious involvement, social support, and health among African-American women on the east side of Detroit," Journal of General Internal Medicine, vol. 18, no. 7, pp. 549-557, 2003.

[37] T. C. Lewis, T. G. Robins, C. L. M. Joseph et al., "Identification of gaps in the diagnosis and treatment of childhood asthma using a community-based participatory research approach," Journal of Urban Health, vol. 81, no. 3, pp. 472-488, 2004.

[38] E. A. Parker, G. T. Baldwin, B. Israel, and M. A. Salinas, "Application of health promotion theories and models for environmental health," Health Education and Behavior, vol. 31, no. 4, pp. 491-509, 2004.

[39] A. J. Schulz, B. A. Israel, and P. Lantz, "Assessing and strengthening characteristics of effective groups in community-based participatory research partnerships," in Handbook of Social Work with Groups, C. D. Garvin, L. M. Gutiérrez, and M. J. Galinsky, Eds., pp. 309-325, Guilford Press, New York, NY, USA, 2004.

[40] A. B. Becker, B. A. Israel, and A. J. Allen III, "Strategies and techniques in effective group process in CBPR partnerships," in Methods in Community-Based Participatory Research for Health, B. A. Israel, E. Eng, A. J. Schulz, and E. A. Parker, Eds., pp. 53-72, Jossey-Bass, San Francisco, Calif, USA, 2005.

[41] K. K. Edgren, E. A. Parker, B. A. Israel et al., "Community involvement in the conduct of a health education intervention and research project: community action against asthma," Health Promotion Practice, vol. 6, no. 3, pp. 263-269, 2005.

[42] B. A. Israel, P. M. Lantz, R. J. McGranaghan, J. R. Guzman, R. Lichtenstein, and Z. Rowe, "Documentation and evaluation of CBPR partnerships," in Methods in Community-Based Participatory Research, B. A. Israel, E. Eng, A. J. Schulz, and E. A. Parker, Eds., pp. 255-277, Jossey-Bass, San Francisco, Calif, USA, 2005.

[43] B. A. Israel, E. A. Parker, Z. Rowe et al., "Communitybased participatory research: lessons learned from the Centers for Children's Environmental Health and Disease Prevention Research," Environmental Health Perspectives, vol. 113, no. 10, pp. 1463-1471, 2005.

[44] E. Parker, T. G. Robins, B. A. Israel, W. Brakefield-Caldwell, K. K. Edgren, and D. J. Wilkins, "Developing and implementing guidelines for dissemination: the experience of the community action against asthma project," in Methods in Community-Based Participatory Research for Health, B. Israel, E. Eng, A. J. Schulz, and E. A. Parker, Eds., pp. 285-306, Jossey-Bass, San Francisco, Calif, USA, 2005.

[45] B. A. Israel, J. Krieger, D. Vlahov et al., "Challenges and facilitating factors in sustaining community-based participatory research partnerships: lessons learned from the Detroit, New York City and Seattle Urban Research Centers," Journal of Urban Health, vol. 83, no. 6, pp. 1022-1040, 2006.

[46] B. A. Israel, A. J. Schulz, L. Estrada-Martinez et al., "Engaging urban residents in assessing neighborhood environments and their implications for health," Journal of Urban Health, vol. 83, no. 3, pp. 523-539, 2006.

[47] E. A. Parker, B. A. Israel, T. G. Robins et al., "Evaluation of Community Action Against Asthma: a community health worker intervention to improve children's asthma-related health by reducing household environmental triggers for asthma," Health Education and Behavior, vol. 35, no. 3, pp. 376-395, 2008.

[48] K. M. Roe, M. Minkler, and F. F. Saunders, "Combining research, advocacy, and education: the methods of the Grandparent Caregiver Study," Health Education Quarterly, vol. 22, no. 4, pp. 458-475, 1995.

[49] K. M. Roe, M. Minkler, F. Saunders, and G. E. Thomson, "Health of grandmothers raising children of the crack cocaine epidemic," Medical Care, vol. 34, no. 11, pp. 1072-1084, 1996.

[50] M. Minkler, "Grandparents as parents: a survival guide for raising a second family," Gerontologist, vol. 39, no. 2, pp. 242245, 1999.

[51] M. Minkler, "Using participatory action research to build healthy communities," Public Health Reports, vol. 115, no. 2-3, pp. 191-197, 2000.

[52] M. Minkler, M. Thompson, J. Bell, and K. Rose, "Contributions of community involvement to organizational-level empowerment: the federal healthy start experience," Health Education and Behavior, vol. 28, no. 6, pp. 783-807, 2001.

[53] M. Minkler, P. Fadem, M. Perry, K. Blum, L. Moore, and J. Rogers, "Ethical dilemmas in participatory action research: a case study from the disability community," Health Education and Behavior, vol. 29, no. 1, pp. 14-29, 2002.

[54] P. Fadem, M. Minkler, M. Perry et al., "Ethical challenges in community based participatory research: a case study from the San Francisco Bay Area disability community," in Community Based Participatory Research for Health, M. Minkler and N. Wallerstein, Eds., Jossey-Bass, San Francisco, Calif, USA, 2003.

[55] P. Fadem, M. Minkler, M. Perry et al., "Attitudes of people with disabilities toward physician-assisted suicide legislation: 
broadening the dialogue," Journal of Health Politics, Policy and Law, vol. 28, no. 6, pp. 977-1001, 2003.

[56] M. Minkler and T. Hancock, "Community-driven asset identification and issue selection," in Community-Based Participatory Research for Health, M. Minkler and N. Wallerstein, Eds., pp. 135-154, Jossey-Bass, San Francisco, Calif, USA, 2003.

[57] M. Themba and M. Minkler, "Influencing policy through community-based participatory research," in CommunityBased Participatory Research for Health, M. Minkler and N. Wallerstein, Eds., pp. 349-369, Jossey-Bass, San Francisco, Calif, USA, 2003.

[58] M. Minkler, "Ethical challenges for the 'outside' researcher in community-based participatory research," Health Education and Behavior, vol. 31, no. 6, pp. 684-697, 2004.

[59] M. Minkler, "Community-based research partnerships: challenges and opportunities," Journal of Urban Health, vol. 82, supplement 2, no. 2, pp. ii3-iil2, 2005.

[60] M. Minkler, V. B. Vásquez, M. Tajik, and D. Petersen, "Promoting environmental justice through community-based participatory research: the role of community and partnership capacity," Health Education \& Behavior, vol. 35, no. 1, pp. 119-137, 2008.

[61] M. Minkler, V. B. Vásquez, J. R. Warner, H. Steussey, and S. Facente, "Sowing the seeds for sustainable change: a community-based participatory research partnership for health promotion in Indiana, USA and its aftermath," Health Promotion International, vol. 21, no. 4, pp. 293-300, 2006.

[62] M. Minkler, V. B. Vásquez, and P. Shepard, "Promoting environmental health policy through community based participatory research: a case study from Harlem, New York," Journal of Urban Health, vol. 83, no. 1, pp. 101-110, 2006.

[63] N. Wallerstein, "Power between evaluator and community: research relationships within New Mexico's healthier communities," Social Science and Medicine, vol. 49, no. 1, pp. 39-53, 1999.

[64] N. Wallerstein, "Community-based prevention: programs that work," Health Education \& Behavior, vol. 27, no. 4, pp. 517-519, 2000.

[65] V. Chavez, B. Duran, Q. E. Baker, M. M. Avila, and N. Wallerstein, "The dance of race and privilege in communitybased participatory research," in Community-Based Participatory Research for Health, M. Minkler and N. Wallerstein, Eds., pp. 81-97, Jossey-Bass, San Francisco, Calif, USA, 2003.

[66] K. C. English, N. Wallerstein, M. Chino et al., "Intermediate outcomes of a tribal community public health infrastructure assessment," Ethnicity \& Disease, vol. 14, no. 3, supplement 1, pp. S61-S69, 2004.

[67] K. Wells, J. Miranda, M. L. Bruce, M. Alegria, and N. Wallerstein, "Bridging community intervention and mental health services research," The American Journal of Psychiatry, vol. 161, no. 6, pp. 955-963, 2004.

[68] N. Wallerstein, B. Duran, M. Minkler, and K. Foley, "Developing and maintaining partnerships with communities," in Methods in Community-Based Participatory Research for Health, B. Israel, E. Eng, A. J. Schulz, and E. A. Parker, Eds., pp. 31-51, Jossey-Bass, San Francisco, Calif, USA, 2005.

[69] L. Romero, N. Wallerstein, J. Lucero, H. G. Fredine, J. Keefe, and J. O'Connell, "Woman to woman: coming together for positive change-using empowerment and popular education to prevent HIV in women," AIDS Education and Prevention, vol. 18, no. 5, pp. 390-405, 2006.

[70] N. Wallerstein, "Commentary: challenges for the field in overcoming disparities through a CBPR approach," Ethnicity \& Disease, vol. 16, supplement 1, no. 1, pp. S146-S148, 2006.
[71] N. B. Wallerstein and B. Duran, "Using community-based participatory research to address health disparities," Health Promotion Practice, vol. 7, no. 3, pp. 312-323, 2006.

[72] A. C. Macaulay, T. Delormier, A. M. McComber et al., "Participatory research with Native community of Kahnawake creates innovative Code of Research Ethics," Canadian Journal of Public Health, vol. 89, no. 2, pp. 105-108, 1998.

[73] A. C. Macaulay, L. E. Commanda, W. L. Freeman et al., "Participatory research maximises community and lay involvement," British Medical Journal, vol. 319, no. 7212, pp. 774-778, 1999.

[74] The Examining Community-Institutional Partnerships for Prevention Research Group, Developing and Sustaining Community-Based Participatory Research Partnerships: A SkillBuilding Curriculum, 2006, http://depts.washington.edu/ccph/ cbpr/intro/intro.php\#i.

[75] J. Jagosh, A. C. Macaulay, P. Pluye et al., "Uncovering the benefits of participatory research: implications of a realist review for health research and practice," Milbank Quarterly, vol. 90, no. 2, pp. 311-346, 2012.

[76] J. M. Westfall, K. Nearing, M. Felzien et al., "Researching together: a CTSA partnership of academicians and communities for translation," Clinical and Translational Science, vol. 6, no. 5, pp. 356-362, 2013.

[77] L. Jones and K. Wells, "Strategies for academic and clinician engagement in community-participatory partnered research," The Journal of the American Medical Association, vol. 297, no. 4, pp. 407-410, 2007.

[78] M. L. Allen, K. A. Culhane-Pera, S. Pergament, and K. T. Call, "A capacity building program to promote CBPR partnerships between academic researchers and community members," Clinical and Translational Science, vol. 4, no. 6, pp. 428-433, 2011.

[79] Centers for Disease Control and Prevention, Basics of Developing Authentic Community-Based Participatory Research Partnerships: Principles and Practices, 2012, http://www.cdc .gov/prc/training/practitoners/basics-of-developing-authenticcommunity.htm.

[80] B. A. Israel, C. M. Coombe, R. McGranaghan et al., "Community-based participatory research: a partnership approach for public health," [CD-ROM], 2009.

[81] D. Parry, J. Salsberg, and A. C. Macaulay, A Guide to Researcher and Knowledge-User Collaboration in Health Research, 2009, http://www.cihr-irsc.gc.ca/e/44954.html.

[82] C. Kennedy, A. Vogel, C. Goldberg-Freeman, N. Kass, and M. Farfel, "Faculty perspectives on community-based research: 'I see this still as a journey," Journal of Empirical Research on Human Research Ethics, vol. 4, no. 2, pp. 3-16, 2009.

[83] M. Mason, B. Rucker, M. Reed et al., "I know what CBPR is, now what do I do?' Community perspectives on CBPR capacity building," Progress in Community Health Partnerships: Research, Education, and Action, vol. 7, no. 3, pp. 235-241, 2013.

[84] N. Norman, S. Cowart, M. Felzien et al., "Testing to prevent colon cancer: how rural community members took on a community-based intervention," Annals of Family Medicine, vol. 11, no. 6, pp. 568-570, 2013.

[85] S. D. Seifer, "Building and sustaining community-institutional partnerships for prevention research: findings from a national collaborative," Journal of Urban Health, vol. 83, no. 6, pp. 9891003,2006 


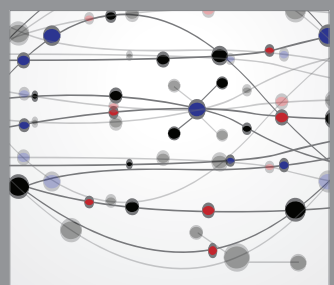

The Scientific World Journal
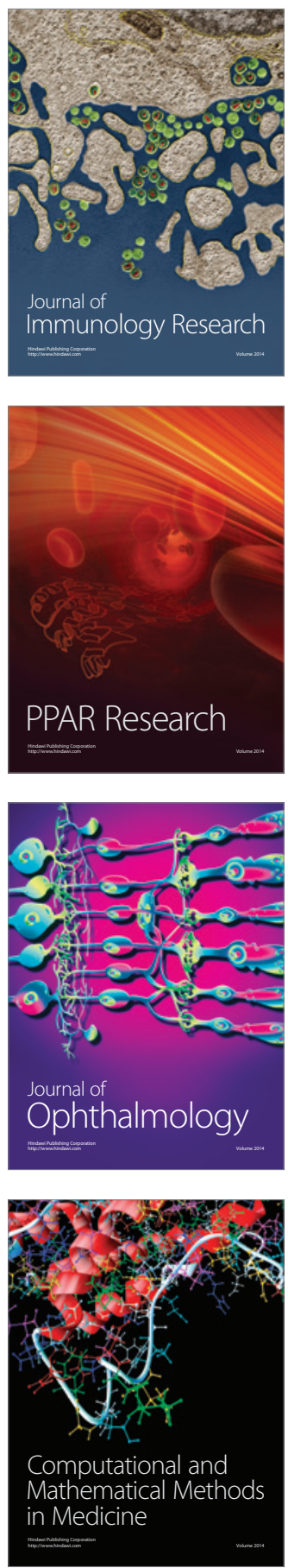

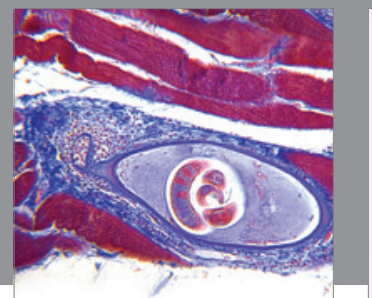

Gastroenterology

Research and Practice
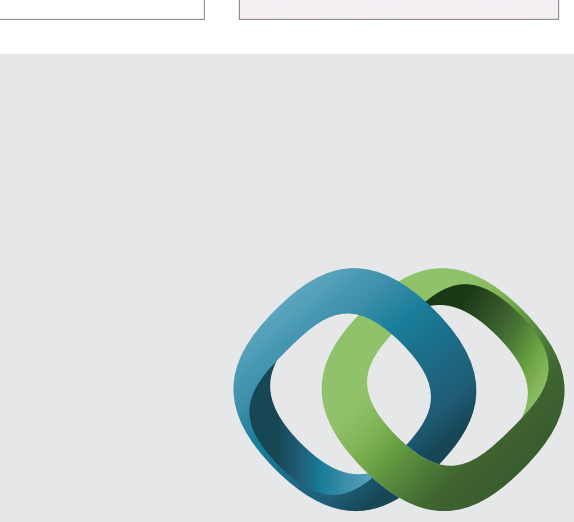

\section{Hindawi}

Submit your manuscripts at

http://www.hindawi.com
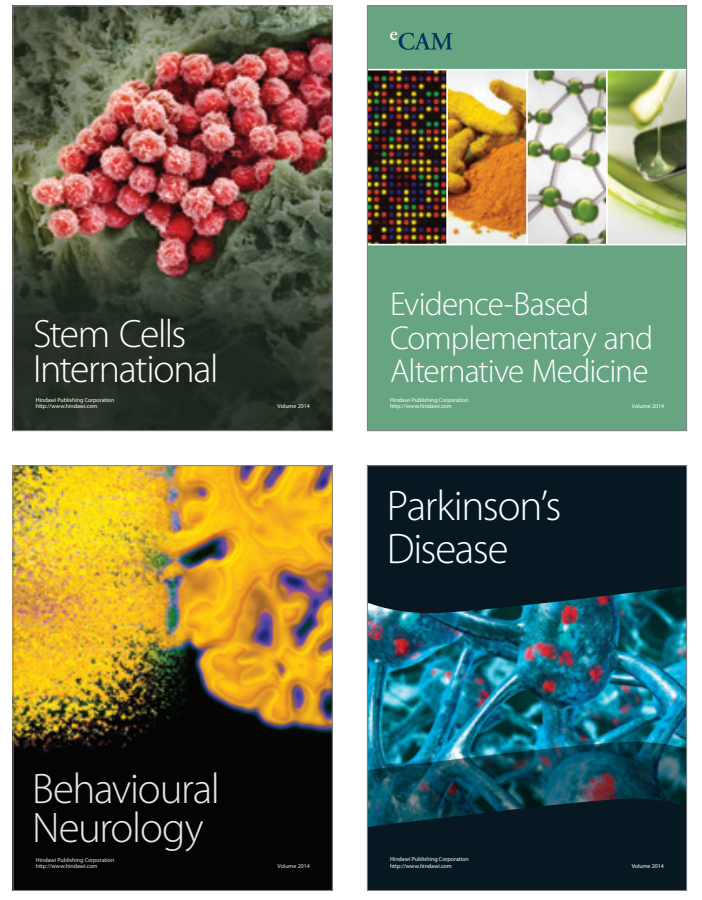
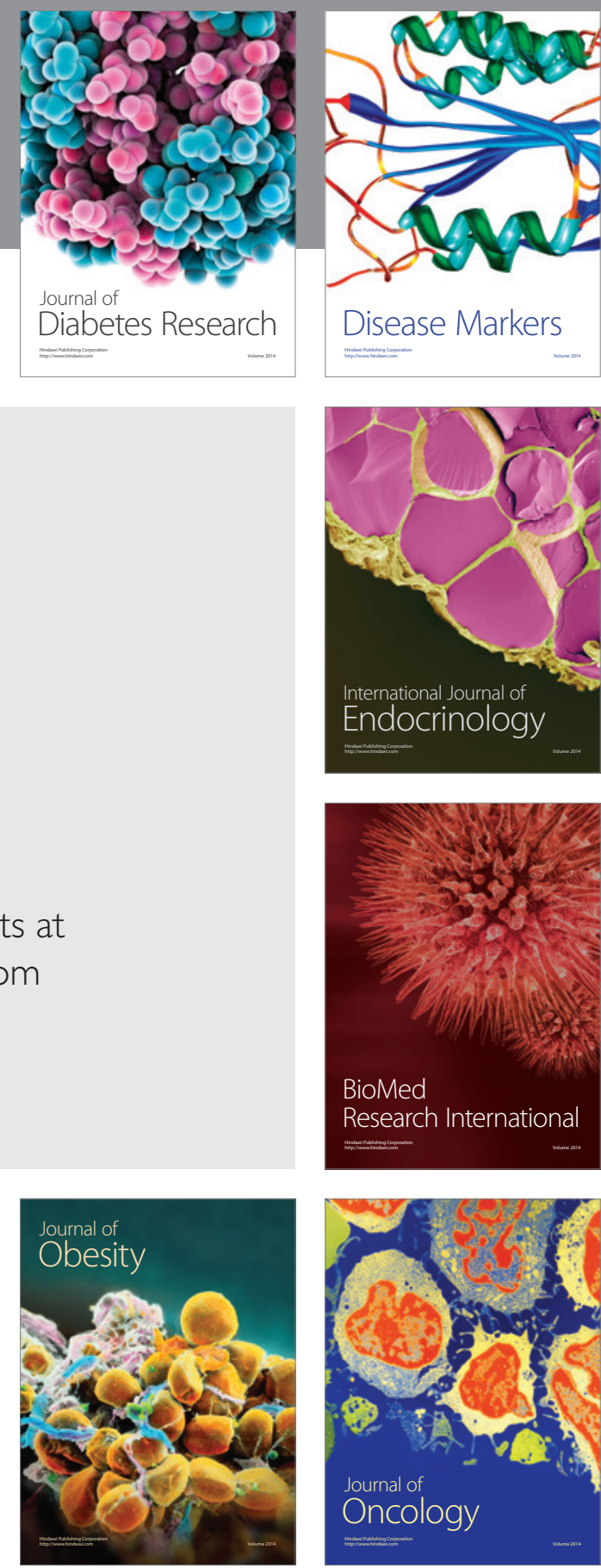

Disease Markers
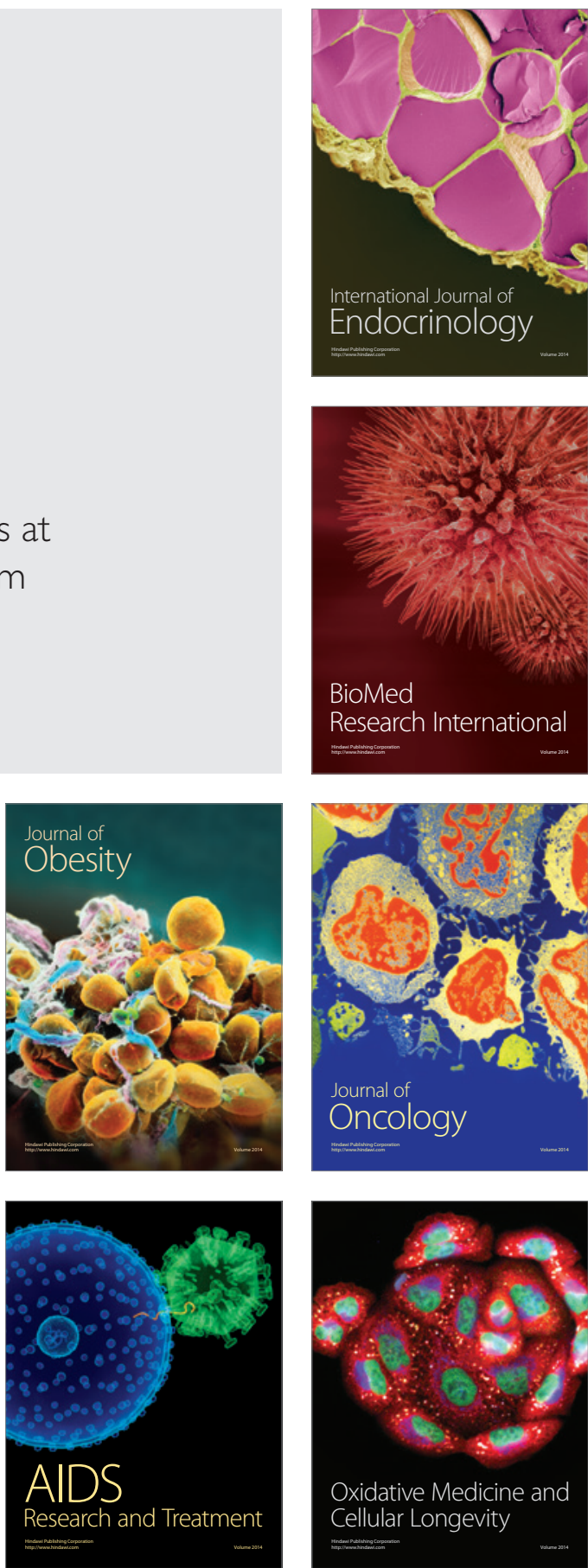